\title{
The Severity of Anastomotic Leakage May Negatively Impact the Long-term Prognosis of Colorectal Cancer
}

\author{
HIDEKAZU TAKAHASHI, NAOTSUGU HARAGUCHI, JUNICHI NISHIMURA, TAISHI HATA, HIROFUMI \\ YAMAMOTO, CHU MATSUDA, TSUNEKAZU MIZUSHIMA, YUICHIRO DOKI and MASAKI MORI \\ Department of Gastroenterological Surgery, Osaka University, Graduate School of Medicine, Suita, Japan
}

\begin{abstract}
Background: Anastomotic leakage is a major critical complication in colorectal resection. Although its relevance to oncological outcome has been widely investigated, the correlation between the severity of anastomotic leakage and oncological outcome is not well understood. Patients and Methods: The clinical characteristics of 615 patients who underwent curative resection of colorectal cancer with anastomosis and normal healing were compared with 44 similar patients who experienced anastomotic leakage. Results: Of the 44 patients, seven had grade A anastomotic leakage, 21 had grade $B$ and 16 had grade $C$. Patients with grade $A$ and $B$ anastomotic leakage were treated conservatively $(n=28)$, and those with grade $C(n=16)$ were treated surgically. Those treated surgically had significantly worse recurrence-free survival and worse cancer-specific survival. Conclusion: Anastomotic leakage had a negative prognostic impact on cancer-specific survival that depended on the severity of anastomotic leakage.
\end{abstract}

The most current statistics from the World Health Organization show that colorectal cancer (CRC) is one of the most common types of cancer worldwide (1). Although recent developments in surgical techniques used for CRC resection have improved the long-term outcomes of patients, recurrence typically occurs within the first 2 years after primary curative surgery. Despite advances in the operative and non-operative management of recurrent CRC, the majority of patients remain incurable and have a median survival of around 2 years (2-8).

Correspondence to: Hidekazu Takahashi, MD, Ph.D. Department of Gastroenterological Surgery, Osaka University, Graduate School of Medicine, 2-2, Yamadaoka, Suita, Osaka, 565-0871, Japan. Tel: +81668793251, Fax: +81668793259, e-mail: htakahashi@ gesurg.med.osaka-u.ac.jp

Key Words: Colorectal cancer, anastomotic leakage, oncological outcome.
In patients with $\mathrm{CRC}$, the prognostic assessment after surgical resection is based largely on tumour-specific characteristics, such as higher pT stage, pN stage, worse tumour differentiation, and vascular and lymphatic invasion, as well as older patient age. Anastomotic leakage (AL), a major and critical complication of colorectal surgery $(9,10)$, is also reported to affect long-term patient outcome, since AL is positively correlated with local recurrence. The reported incidence of local recurrence ranges from $0.5 \%$ to $30 \%$, depending on the detection method and the type of anastomosis $(11,12)$.

Different groups have assessed the impact of AL on systemic recurrence and local recurrence of CRC $(10,13-$ 15). AL after curative surgery causes severe systemic inflammation, which correlates with poor long-term outcome in patients with several types of cancers. Recent cell- and animal-based studies support these findings and further show that systemic inflammation leads to micrometastasis due to the high affinity of cancer cells for vascular endothelial cells and to the progression of micrometastases to clinically apparent metastases $(16,17)$. Moreover, non-steroidal antiinflammatory drugs suppress initiation and promotion of colon cancer (18-20), supporting a link between inflammation and cancer (16). Taken together, these findings suggest that surgeons should carefully manage patients with AL who have a low level of inflammation.

The International Study Group of Rectal Cancer has defined and graded AL according to its severity (21). However, no long-term data from patients who have undergone curative resection for CRC have been analysed according to the severity of AL. The present retrospective study aimed to evaluate the prognostic impact of the severity of $\mathrm{AL}$ after curative resection with anastomosis in patients with CRC.

\section{Patients and Methods}

Inclusion criteria. We retrospectively analysed a total of 1481 consecutive patients who underwent colorectal surgery at Osaka University Hospital between January 2001 and June 2012. Patients 
were excluded if recurrent or metastatic disease was confirmed preoperatively or during surgery, or if they had benign or stage IV tumours or operation without anastomosis, or if their long-term data were unavailable. All recorded clinical and pathological data were re-validated based on medical and pathological records. Data were collected regarding age, sex, body mass index (BMI), primary tumour site, surgical approach, histological grade and TNM stage according to the seventh version of the classification of the Union for International Cancer Control (22). Within 3 weeks before surgery, laboratory blood tests were performed to determine the serum carcinoembryonic antigen (CEA) level. This retrospective study was approved by our Institutional Review Board (approval number 15144).

Anastomotic leakage. In this study, AL was diagnosed when peritonitis caused by leakage, pelvic abscess, or the discharge of faeces, pus or gas from the abdominal drain was observed. AL was defined according to the criteria proposed by the International Study Group of Rectal Cancer (21). Briefly, radiological leakage requiring no active therapeutic interventions was categorized as grade $\mathrm{A}, \mathrm{AL}$ requiring active therapeutic interventional radiology that was manageable without re-laparotomy was categorized as grade B and that requiring re-laparotomy was categorized as grade $\mathrm{C}$. Grade $\mathrm{A}$ and e B AL was termed conservatively treated $\mathrm{AL}$, and grade $\mathrm{C} \mathrm{AL}$ was categorized as surgically treated AL.

Surveillance. After CRC resection, the surveillance schedule was based on the guidelines of the Japanese Society for Cancer of the Colon and Rectum (23). Briefly, physical examination, serum CEA, chest-X ray and an abdominal computed tomographic (CT) scan were performed at least every 6 months after surgery for 3 years and annually thereafter. Other examinations, such as colonoscopy or chest CT scan, were performed according to patient status.

Diagnosis of recurrence. Diagnosis of recurrence was performed by observation over time using positron-emission tomography-CT, magnetic resonance imaging, or histological examination. Definitive diagnosis of recurrence in this study was confirmed retrospectively.

Statistical analysis. The outcome measures were recurrence-free survival, which was measured as the duration from surgery to any recurrence, and cancer-specific survival, which was measured as the duration from surgery to all-cause cancer-specific death. The KaplanMeier method and the log-rank test were used for survival analysis. Univariate analyses of recurrence-free survival and cancer-specific survival were conducted using the Cox proportional hazards model to identify potential prognostic factors of survival; variables that gave $p$-values of less than 0.05 in univariate analysis were included in a Cox multivariate regression model to investigate independent predictors of recurrence-free and cancer-specific survival in CRC; a $p$-value of less than 0.05 was considered to indicate statistical significance. All statistical analyses were performed using JMP Pro Version 12 (SAS Institute, Inc., Cary, NC, USA).

\section{Results}

Patient characteristics. A total of 1,481 patients underwent colorectal resection from January 2001 to June 2012 at our Institute. Of these, 285 patients did not have primary anastomosis, 228 patients did not have CRC, 136 patients

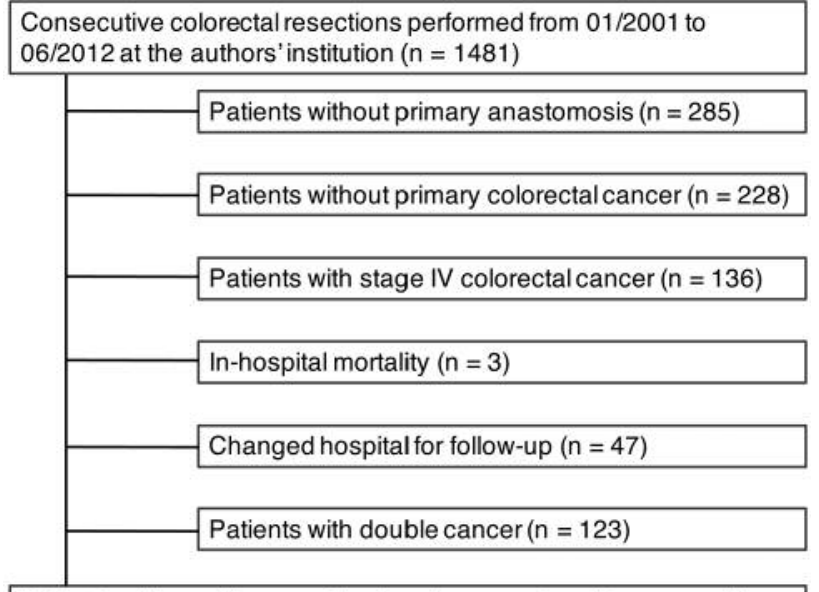

Patients with curative resection for primary colorectal cancer with primary anastomosis $(n=659)$

Figure 1. Flowchart of patients included in the study.

had stage IV CRC, three patients died in the hospital (two due to systemic inflammatory response syndrome followed by AL and one patient due to pneumonia) and 47 patients changed hospitals for further surveillance. Thus, a total of 659 patients with CRC who underwent curative resection with anastomosis were enrolled in this study (Figure 1). The incidence of AL was $6.7 \%$ (44/659). Seven patients were categorised as having AL of grade A, 21 with grade $\mathrm{B}$, and 16 with grade $\mathrm{C}$. Of the cases with grade $\mathrm{C} A \mathrm{AL}$, two died inhospital. The median follow-up for survivors was 64.6 months (interquartile range $=48.7-86.9$ months). During the follow-up period, $70 / 659$ patients $(10.6 \%)$ patients died, and 48 deaths $(68.6 \%)$ were cancer-specific. Cancer recurrence was observed in 103/659 patients (15.6\%). Patient clinical and pathological data are shown in Table I.

Prognostic value of $A L$ in disease-free and disease-specific survival. Since the number of patients with grade A AL was too small to analyse, grade A and grade B AL cases were categorized as conservatively treated $\operatorname{AL}(n=28)$, while grade $\mathrm{C}$ was categorized as surgically treated AL $(n=16)$. Thirtyseven patients in the group with no leakage, two in the conservatively treated group, and five in the surgically treated group died from primary cancer. Recurrence was observed in 90, five and five patients, respectively.

To address the impact of AL on disease-specific longterm outcome, Kaplan-Meier analysis was performed to assess the effect of AL on disease-free survival and diseasespecific survival. The disease-free survival rate was significantly different in the no-leakage, and conservatively treated AL groups versus the surgically treated AL group 


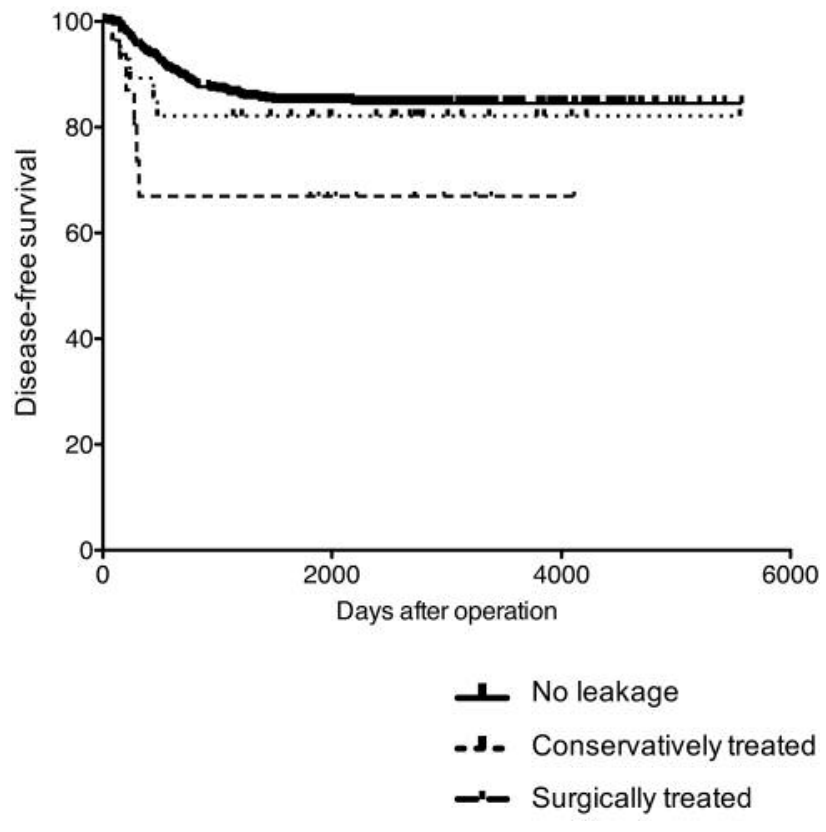

Figure 2. Kaplan-Meier curves for disease-free survival according to anastomotic leakage category. Disease-free survival was significantly worse in the surgically-treated $A L$ group than in the no-leakage group $(p<0.05)$.

$(p<0.05$, Figure 2). Univariate analysis showed that disease-free survival was significantly worse in the surgically treated AL group than in the no-leakage group $(p<0.05)$; however, no significant differences were found in the other pairwise group comparisons (Figure 2). Local recurrence was observed in a total of 10 patients, including eight patients in the no-leakage group, one in the conservatively treated group and one in the surgicallytreated group. The disease-specific survival rate of the noleakage conservatively-treated AL group was significantly better than that of the surgically-treated AL group $(p<0.001$, Figure 3). There was no difference in diseasespecific survival between the conservatively treated AL group and the no-leakage group $(\mathrm{p}=0.70)$, but diseasespecific survival of the surgically treated leakage group was significantly worse than that of the no-leakage group $(p<0.001)$, and that of the conservatively treated AL group $(p<0.05)$.

Cox proportional hazards model for disease-specific survival. A Cox proportional hazards model was used to support the data from the Kaplan-Meier analysis regarding disease-specific survival. Cox regression analysis, which included age, sex, tumour site, tumour grade, T-stage, $\mathrm{N}$ stage and AL treatment strategy showed that tumour grade $(p<0.05)$, T-stage $(p<0.0001), \mathrm{N}$-stage $(p<0.0001)$ and AL

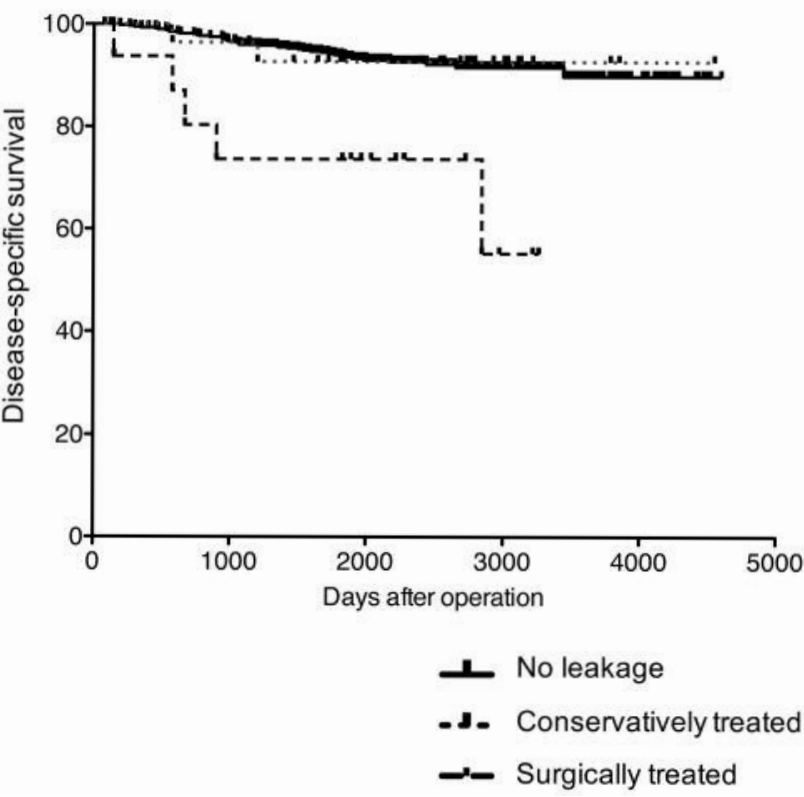

Figure 3. Kaplan-Meier curves for disease-specific survival according to anastomotic leakage $(A L)$ category. Disease-specific survival rate of the no-leakage conservatively-treated $A L$ group was significantly better than that of the surgically-treated AL group $(p<0.001)$. Disease-specific survival of the surgically-treated $A L$ group was significantly worse than that of no-leakage group $(p<0.001)$, and that of the conservativelytreated AL group $(p<0.05)$.

$(p<0.05)$ each had an independent effect on disease-specific survival $(p<0.001$, Table II). In the multivariate model, Nstage $(p<0001)$ and AL $(p<0.05)$ each had a negative impact on disease-specific survival (Table II).

Assessment of the severity of $A L$. To assess the severity of AL in each group, peak white blood cell (WBC) counts and the C-reactive protein (CRP) level after surgery were analysed in each group as subjective indicators. The peak WBC count and the peak CRP value after surgery were both significantly higher than for patients with conservatively treated AL (Table III, patients with grade A or grade B AL, $p<0.05)$. These results suggest that patients categorized with grade $\mathrm{C}$ AL had more severe inflammation than those with grade A AL.

\section{Discussion}

The present study demonstrated that patients with AL that had unavoidable reoperations had poorer overall survival than patients with AL that was treated conservatively. In other words, the severity of the AL might be associated with the long-term outcomes of patients with CRC. 
Table I. The characteristics of patients with and without anastomotic leakage after colorectal resection.

\begin{tabular}{|c|c|c|c|c|c|c|}
\hline \multirow[b]{3}{*}{ Characteristic } & \multirow[b]{3}{*}{$(\mathrm{n}=615)$} & \multirow[b]{3}{*}{ No leakage } & \multicolumn{4}{|c|}{ Anastomotic leakage } \\
\hline & & & \multirow[b]{2}{*}{$\begin{array}{l}\text { Leakage, all grades } \\
\qquad(\mathrm{n}=44)\end{array}$} & \multicolumn{2}{|c|}{$\begin{array}{c}\text { Conservatively } \\
\text { treated }\end{array}$} & \multirow{2}{*}{$\begin{array}{c}\begin{array}{c}\text { Surgically } \\
\text { treated }\end{array} \\
\begin{array}{c}\text { Grade } \mathrm{C} \\
(\mathrm{n}=16)\end{array}\end{array}$} \\
\hline & & & & $\begin{array}{c}\text { Grade A } \\
(\mathrm{n}=7)\end{array}$ & $\begin{array}{c}\text { Grade B } \\
(\mathrm{n}=21)\end{array}$ & \\
\hline Age, years & Mean \pm SD & $64.5 \pm 11.2$ & $62.9 \pm 11.0$ & $63.6 \pm 11.3$ & $62.8 \pm 9.5$ & $60.6 \pm 12.9$ \\
\hline \multirow[t]{2}{*}{ Gender, n (\%) } & Male & $359(58.4)$ & $33(75.0)$ & $3(42.9)$ & $16(76.2)$ & $14(87.5)$ \\
\hline & Female & $256(41.6)$ & $11(25.0)$ & $4(57.1)$ & $5(23.8)$ & $2(12.5)$ \\
\hline Body mass index, $\mathrm{kg} / \mathrm{m}^{2}$ & Mean \pm SD & $22.7 \pm 3.5$ & $24.3 \pm 4.3$ & $25.1 \pm 2.2$ & $25.1 \pm 5.2$ & $22.7 \pm 3.5$ \\
\hline \multirow[t]{5}{*}{ Tumour location, n (\%) } & $\mathrm{V}, \mathrm{C}, \mathrm{A}$ & $140(22.8)$ & $3(6.82)$ & $1(14.3)$ & $2(9.5)$ & $0(0.00)$ \\
\hline & $\mathrm{T}$ & $56(9.1)$ & $1(2.3)$ & $1(14.3)$ & $0(0.00)$ & $0(0.00)$ \\
\hline & $\mathrm{D}$ & $18(2.9)$ & $1(2.3)$ & $0(0.00)$ & $0(0.00)$ & $1(6.3)$ \\
\hline & $\mathrm{S}$ & $207(33.7)$ & $7(15.9)$ & $1(14.3)$ & $3(14.3)$ & $3(18.8)$ \\
\hline & $\mathrm{R}$ & $194(31.5)$ & $32(72.7)$ & $4(57.1)$ & $16(76.2)$ & $12(75.0)$ \\
\hline \multirow[t]{4}{*}{ Tumour depth, n (\%) } & $\mathrm{T} 1$ & $169(27.5)$ & $6(13.6)$ & $1(14.3)$ & $4(19.1)$ & $1(6.3)$ \\
\hline & $\mathrm{T} 2$ & $134(21.8)$ & $11(25.0)$ & $1(14.3)$ & $5(23.8)$ & $5(31.3)$ \\
\hline & $\mathrm{T} 3$ & 275 & $21(47.7)$ & $5(71.4)$ & $9(42.9)$ & $7(43.8)$ \\
\hline & $\mathrm{T} 4$ & $37(6.0)$ & $6(13.6)$ & $0(0.0)$ & $3(14.3)$ & $3(18.8)$ \\
\hline \multirow{3}{*}{ Lymph node metastasis, n (\%) } & No & $420(68.3)$ & $32(72.7)$ & $5(71.4)$ & $15(71.4)$ & $12(75.0)$ \\
\hline & N1 & $150(24.4)$ & $9(20.5)$ & $1(14.3)$ & $4(19.1)$ & $4(25.0)$ \\
\hline & $\mathrm{N} 2$ & $45(7.3)$ & $3(6.8)$ & $1(14.3)$ & $2(9.52)$ & $0(0.0)$ \\
\hline Preoperative CEA level, ng/ml & Mean \pm SD & $9.5 \pm 8.7$ & $7.3 \pm 16.3$ & $15.3 \pm 41.4$ & $7.0 \pm 11.4$ & $4.4 \pm 3.7$ \\
\hline \multirow[t]{2}{*}{ Neoadjuvant chemotherapy, n (\%) } & Yes & $16(2.6)$ & $3(6.8)$ & $1(14.3)$ & $1(4.8)$ & $1(6.3)$ \\
\hline & No & $599(97.4)$ & $41(93.2)$ & $6(85.7)$ & $20(95.2)$ & $15(93.7)$ \\
\hline \multirow[t]{2}{*}{ Adjuvant chemotherapy, n (\%) } & Yes & $184(29.9)$ & $12(27.3)$ & $3(43.9)$ & $4(19.1)$ & $5(31.3)$ \\
\hline & No & $431(70.1)$ & $32(72.7)$ & $4(57.1)$ & $17(81.0)$ & $11(68.8)$ \\
\hline \multirow{2}{*}{ Laparoscopic surgery, n (\%) } & Yes & $437(71.1)$ & $19(43.2)$ & $4(57.1)$ & $7(33.3)$ & $8(50.0)$ \\
\hline & No & $178(28.9)$ & $25(56.8)$ & $3(42.9)$ & $14(66.7)$ & $8(50.0)$ \\
\hline \multirow[t]{2}{*}{ Combined resection of other organ, $\mathrm{n}(\%)$} & Yes & $51(8.3)$ & $8(18.2)$ & $1(20.0)$ & $3(14.3)$ & $4(25.0)$ \\
\hline & No & $564(91.7)$ & $36(81.8)$ & $6(80.0)$ & $18(85.7)$ & $12(75.0)$ \\
\hline \multirow[t]{2}{*}{ Diverting stoma, $\mathrm{n}(\%)$} & Yes & $58(9.4)$ & $7(18.9)$ & $1(14.3)$ & $7(33.3)$ & $0(0.0)$ \\
\hline & No & $557(90.6)$ & $30(81.1)$ & $6(85.7)$ & $14(66.7)$ & $16(100.0)$ \\
\hline
\end{tabular}

V: Vermiform process; C: cecum; A: ascending colon; T: transverse colon; D: descending colon; S: sigmoid colon; R: rectum; CEA: carcinoembryonic antigen; SD: standard deviation.

Although AL is a highly-feared early complication after surgical treatment of CRC that is associated with high morbidity and mortality, the impact of AL on longer-term oncological outcomes such as local recurrence, distant recurrence and survival remains a matter of debate. Recurrence after AL is most commonly local, and several groups have reported increased local tumour recurrence after $\mathrm{AL}$ in patients who underwent resection for $\mathrm{CRC}$, as summarised in the meta-analysis by Mirnezami et al. (12), which focused on studies conducted before 2009 , and that by Lu et al. (11), which focused on studies conducted after 2003. Both concluded that AL after curative resection for CRC has an adverse impact on cancer-specific local recurrence and thus survival. Although these findings have been substantiated by additional studies (14, 15, 25-27), other groups have reported contradictory findings $(10,13$,
28, 29). For example, Eriksen et al. found no significant increase in recurrence after AL in a study of 1958 patients from the Norwegian Rectal Cancer Registry (29). There were some differences in these previous reports in terms of, for example, the historical background, the number of cases and the $\mathrm{AL}$ rates, suggesting that the short- and long-term outcomes of AL that accompanies curative surgery for CRC might vary in the different reports. In the present study, although the local recurrence rate of the AL patients was significantly higher than that of the no-leakage patients [5.4\% (2/37) versus $1.2 \%(10 / 782) ; p<0.05$, Pearson's test], the event number was too small for further subgroup analysis.

In terms of the long-term cancer-specific survival of patients of $\mathrm{AL}$ with $\mathrm{CRC}$, it is possible that the inflammatory response associated with $\mathrm{AL}$ could itself 
Table II. Clinical, histopathological characteristics and Cox proportional hazards models predicting cancer-specific survival for patients who underwent curative colorectal resection with anastomosis.

\begin{tabular}{|c|c|c|c|c|c|c|}
\hline \multirow[b]{2}{*}{ Variable } & & \multirow[b]{2}{*}{ Value } & \multicolumn{2}{|c|}{ Univariate analysis } & \multicolumn{2}{|c|}{ Multivariate analysis } \\
\hline & & & Hazard ratio $(95 \% \mathrm{CI})$ & $p$-Value & Hazard ratio $(95 \% \mathrm{CI})$ & $p$-Value \\
\hline Age, years & Median (range) & $65(58-72)$ & $1.00(0.98-1.03)$ & 0.74 & & NA \\
\hline \multirow[t]{2}{*}{ Gender, n (\%) } & Male & $392(59.7 \%)$ & 1 & 0.64 & & NA \\
\hline & Female & $265(40.3 \%)$ & $0.87(0.48-1.54)$ & & & \\
\hline \multirow{2}{*}{ Site, n (\%) } & Colon & $433(65.7 \%)$ & 1 & 0.28 & & NA \\
\hline & Rectum & $226(34.3 \%)$ & $1.37(0.76-2.42)$ & & & \\
\hline \multirow[t]{2}{*}{ Tumour grade, n (\%) } & Tub1/tub2 & $623(94.5 \%)$ & 1 & 0.29 & 1 & 0.37 \\
\hline & Poor/muc & $36(5.5 \%)$ & $1.75(0.53-4.32)$ & & $1.46(0.59-3.09)$ & \\
\hline \multirow[t]{4}{*}{ T-Stage, n (\%) } & 1 & $175(26.6 \%)$ & 1 & $<0.0001$ & 1 & 0.061 \\
\hline & 2 & $145(22.0 \%)$ & $3.73(0.86-25.5)$ & & $2.27(0.51-15.8)$ & \\
\hline & 3 & $296(44.9 \%)$ & $9.27(2.80-57.3)$ & & $4.34(1.22-27.6)$ & \\
\hline & 4 & $43(6.5 \%)$ & $22.7(5.97-147.5)$ & & $6.65(1.56-45.9)$ & \\
\hline \multirow[t]{3}{*}{ N-Stage, n (\%) } & 0 & $546(69.8 \%)$ & 1 & $<0.0001$ & 1 & $<0.0001$ \\
\hline & 1 & $180(23.0 \%)$ & $5.18(2.64-10.6)$ & & $3.60(1.80-7.55)$ & \\
\hline & 2 & $56(7.2 \%)$ & $11.9(5.43-26.0)$ & & $8.16(3.54-19.0)$ & \\
\hline \multirow[t]{3}{*}{$\mathrm{AL}, \mathrm{n}(\%)$} & No leakage & $615(93.3 \%)$ & 1 & $<0.05$ & 1 & $<0.005$ \\
\hline & Conservatively treated & $28(4.2 \%)$ & $0.98(0.16-3.18)$ & & $0.74(0.12-2.49)$ & \\
\hline & Surgically treated & $16(2.4 \%)$ & $5.53(1.91-12.8)$ & & $5.69(1.88-14.1)$ & \\
\hline
\end{tabular}

Tub1: Well differentiated adenocarcinoma; tub2: moderately differentiated adenocarcinoma; poor: poorly differentiated adenocarcinoma; muc: mucinous adenocarcinoma; AL: Anastomotic leakage; CI: confidence interval; IQR: interquartile range; NA: not applicable.

Table III. Peak levels of inflammatory indicators in each group (mean $\pm S D)$.

\begin{tabular}{|c|c|c|c|c|}
\hline \multirow[b]{2}{*}{ Indicator } & \multicolumn{2}{|c|}{ Conservatively treated } & \multirow{2}{*}{$\begin{array}{l}\text { Surgically-treated } \\
\text { Grade C }(n=16)\end{array}$} & \multirow[t]{2}{*}{$p$-Value } \\
\hline & Grade A $(n=5)$ & Grade B $(n=16)$ & & \\
\hline Peak WBC, $n / \mu l$ & $9244 \pm 1177$ & $13315 \pm 4989$ & $17725 \pm 9207$ & $<0.05$ \\
\hline Peak CRP, mg/dl & $10.4 \pm 4.47$ & $23.0 \pm 6.45$ & $25.7 \pm 8.94$ & $<0.05$ \\
\hline Hospital stay, days & $22.6 \pm 7.5$ & $64.5 \pm 30.8$ & $48.9 \pm 25.6$ & NS \\
\hline Peak WBC, $\mathrm{n} / \mu \mathrm{l}$ & \multicolumn{2}{|c|}{$12297 \pm 4610$} & & $<0.05$ \\
\hline Peak CRP, mg/dl & \multicolumn{2}{|c|}{$19.8 \pm 7.49$} & & $<0.05$ \\
\hline Hospital stay, days & \multicolumn{2}{|c|}{$54.5 \pm 32.5$} & & NS \\
\hline
\end{tabular}

CRP: C-Reactive protein; NS: not significant; WBC: white blood cells.

facilitate cancer recurrence. During the acute and subsequent chronic inflammation that accompanies AL, a variety of acute-phase reactants and pro-inflammatory mediators are released both locally and systemically. After a local inflammatory reaction, local site recurrence may emerge (30). For systemic reactions, an increasing number of experimental studies in recent years have demonstrated that many inflammatory biomarkers are implicated in tumour cell proliferation, survival, avoidance of apoptosis, progression to metastasis and resistance to drug therapy. For example, interleukin-1 (IL1) can enhance the growth and progression of CRC $(31,32)$. Notably, IL1 is highly expressed in advanced cases, and IL1 antagonists inhibited tumour growth in experimental models. It is therefore conceivable that high IL1 levels, either systemically or locally, may sustain exfoliated cancer cells, providing the survival and growth signals needed to promote recurrence at a later date. Nojiri et al. suppressed tumour metastasis by targeting guanylyl cyclase-A (GC-A), an inflammationrelated target of nuclear factor kappa-B (NF-kB), using atrial natriuretic peptide (17). More recently, endothelial death receptor 6 , a well known NF-kB target, was found to act as the primary mediator of cancer cell extravasation and metastasis in vivo and in vitro (33). 
The notion that an inflammatory response may promote CRC recurrence is further supported by data from other cancer types. In breast cancer, several authors have suggested that inflammation plays a role in disease recurrence (34-36). Murthy et al. noted a significant relationship between infective wound complications after primary breast cancer resection and subsequent tumour recurrence (34). Pierce et al. studied the relationship between markers of inflammation and overall and diseasefree survival from breast cancer. In their study of 659 patients, elevated markers of inflammation were significantly associated with reduced overall and diseasefree survival (35). Saito et al. studied 305 patients who underwent curative surgery for pT2-T4b gastric cancer and found that CRP elevation is a more reliable indicator of survival after gastric cancer surgery than the occurrence of postoperative complication (36). According to this hypothesis, systemic recurrence, as well as local recurrence, would be expected to be higher in patients with AL after curative surgery for CRC.

With regard to re-operation requiring general anaesthesia, one study report that anaesthetics themselves may cause immune suppression (37). By modulating the neurohumoral stress response, anaesthetics and analgesics can also independently suppress immune function (37). Surgical trauma accompanied by adrenergic activation can directly potentiate cancer cell growth (38). According to this evidence, re-operation requiring general anaesthesia might have an undesirable effect on micrometastasis.

This study had a number of limitations. Firstly, the retrospective study design may have led to selection bias. Secondly, the use of data from a single institution may limit the wider applicability of our findings. Thirdly, this assessment was performed on a small sample of patients. Finally, we did not address recent development of technologies and peripheral equipment for interventional radiology, which have rapidly changed the management of patients suffering from AL (39).

\section{Conclusion}

Our data demonstrate that the severity of AL was associated with poor long-term outcomes in patients who underwent curative surgery for CRC. Although further prospective studies are needed to clarify the effects of AL in patients with CRC, this finding has implications for the management of AL after CRC resection.

\section{Conflicts of Interest}

The Authors declare that they have no conflicts of interest in regard to this study.

\section{References}

1 Torre LA, Bray F, Siegel RL, Ferlay J, Lortet-Tieulent L and Jemal A: Global cancer statistics, 2012. CA Cancer J Clin 65: 87-108, 2015.

2 Bakx R, Visser O, Josso J, Meijer S, Slors FM and Lanschot JB: Management of recurrent rectal cancer: a population based study in greater Amsterdam. World J Gastroenterol 14: 6018-6023, 2008.

3 Cunningham D, Humblet Y, Siena S, Khayat D, Bleiberg H, Santoro A, Bets D, Mueser M, Harstrick A, Verslype C, Chau I and Cutsem EV: Cetuximab monotherapy and cetuximab plus irinotecan in irinotecan-refractory metastatic colorectal cancer. N Engl J Med 351: 337-345, 2004.

4 de Gramont A, Figer A, Seymour M, Homerin M, Hmissi A, Cassidy J, Boni C, Cortes-Funes H, Cervantes A, Fryer G, Papamicheal D, Le Bail N, Louvet C, Hendler D, de Braud F, Wilson C, Morvan F and Bonetti A: Leucovorin and fluorouracil with or without oxaliplatin as first-line treatment in advanced colorectal cancer. Journal of Clinical Oncology 18: 2938-2947, 2000.

5 Douillard J, Cunningham D, Roth AD, Navarro M, James RD, Karaesk P, Jandik P, Iveson T, Carmichael J, Alakl M, Gruia G, Awad L and Rougier P: Irinotecan combined with fluorouracil compared with fluorouracil alone as first-line treatment for metastatic colorectal cancer: a multicentre randomised trial. The Lancet 355: 1041-1047, 2000.

6 Hurwitz H, Fehrenbacher L, Novotny W, Cartwright T, Hainsworth J, Heim W, Berlin J, Baron A, Griffing S, Holmgern E, Ferrara N, Fyfe G, Rogers B, Ross R and Kabbinavar F: Bevacizumab plus irinotecan, fluorouracil, and leucovorin for metastatic colorectal cancer. N Engl J Med 350: 2335-2342, 2004.

7 Ito Y, Ohtsu A, Ishikuwa S, Boku N, Nihei K, Ogino T and Ikeda H: Efficacy of chemoradiotherapy on pain relief in patients with intrapelvic recurrence of rectal cancer. Jpn J Clin Oncol 33: 180-185, 2003.

8 Wong CS, Cummings BJ, Brierley JD, Catton CN, McLean M, Catton $\mathrm{P}$ and Hao Y: Treatment of locally recurrent rectal carcinoma - results and prognostic factors. Int J Radiat Oncol Biol Phys 40: 427-435, 1998.

9 Snijders H, Wouters MWJM, van Leersum NJ, Kolfschoten NE, Henneman D, de Vries AC, Tollenaar RAEM and Bonsing BA: Meta-analysis of the risk for anastomotic leakage, the postoperative mortality caused by leakage in relation to the overall postoperative mortality. Eur J Surg Oncol 38: 1013-1019, 2012.

10 den Dulk M, Marijnen CAM, Collette L, Putter H, Pahman L, Folkesson J, Bosset JF, Rodel C, Bujko K and van de Velde CJ: Multicentre analysis of oncological and survival outcomes following anastomotic leakage after rectal cancer surgery. Br J Surg 96: 1066-1075, 2009.

11 Zheqin L, Lynch N, Craig A, Alexander H and Satish W: Anastomotic leaks after restorative resections for rectal cancer compromise cancer outcomes and survival. Dis Colon Rectum 59: 236-244, 2016.

12 Mirnezami A, Mirnezami R, Chandrakumaran K, Sasapu K, Sagar P and Finan P: Increased local recurrence and reduced survival from colorectal cancer following anastomotic leak: systematic review and meta-analysis. Ann Surg 253: 890-899, 2011. 
13 Akyol A, McGregor JR, Galloway DJ and Gerge WD: Anastomotic leaks in colorectal cancer surgery: a risk factor for recurrence? Int J Colorectal Dis 6: 179-183, 1991.

14 Docherty JG, McGregor JR, Murray GD and Galloway DJ: Comparison of manually constructed and stapled anastomoses in colorectal surgery. West of Scotland and Highland Anastomosis Study Group. Ann Surg 221: 176-184, 1995.

15 Fujita S, Teramoto T, Watanabe M, Kodaira S and Kitajima M: Anastomotic leakage after colorectal cancer surgery: a risk factor for recurrence and poor prognosis. Jpn J Clin Oncol 23: 299 302, 1993.

16 Clevers H: At the crossroads of inflammation and cancer. Cell 118: 671-674, 2004.

17 Nojiri T, Hosoda H, Tokudome T, Miura K, Ishikane S, Otani K, Kishimoto I, Shintani Y, Inoue M, Kimura T, Sawabata N, Minami M, Nakagiri T, Funaki S, Takeuchi Y, Maeda H, Kidoya H, Kiyonari H, Shioi G, Arai Y, Hasegawa T, Takakura N, Hori M, Ohno Y, Miyazato M, Mochizuki N, Okumura M and Kangawa K: Atrial natriuretic peptide prevents cancer metastasis through vascular endothelial cells. Proc Natl Acad Sci USA 112: 4086-4091, 2015.

18 Chan TA: Nonsteroidal anti-inflammatory drugs, apoptosis, and colon-cancer chemoprevention. Lancet Oncol 3: 166-174, 2002.

19 Thun MJ, Namboodiri MM and Heath CW Jr.: Aspirin use and reduced risk of fatal colon cancer. N Engl J Med 325: 15931596, 1991.

20 Tsujii M, Kawano S and DuBois RN: Cyclooxygenase-2 expression in human colon cancer cells increases metastatic potential. Proc Natl Acad Sci USA 94: 3336-3340, 1997.

21 Rahbari NN, Weitz J, Hohenberger W, Heald RJ, Moran B, Ulich A, Holm T, Wong WD, Tiret E, Moriya Y, Laurberg S, den Dulk $M$, van de Velde $C$ and Buchler MW: Definition and grading of anastomotic leakage following anterior resection of the rectum: a proposal by the International Study Group of Rectal Cancer. Surgery 147: 339-351, 2010.

22 Edge SB and Compton CC: The American Joint Committee on Cancer: the 7th edition of the AJCC cancer staging manual and the future of TNM. Ann surg Oncol 17: 1471-1474, 2010.

23 Watanabe T, Itabashi M, Shimada Y, Tanaka S, Ito Y, Ajioka Y, Hamaguchi T, Hyodo I, Igarashi M, Ishida H, Ishihara S, Ishiguro M, Kanemitsu Y, Kokudo N, Muro K, Ochiai A, Oguchi M, Ohkura Y, Saito Y, Sakai Y, Ueno H, Yoshino T, Boku N, Fujimori T, Koinuma N, Morita T, Nishimura G, Sakata Y, Takahashi K, Tsuruta O, Yamaguchi T, Yoshida M, Yamaguchi N, Kotake K and Sugihara K: Japanese Society for Cancer of the Colon and Rectum (JSCCR) Guidelines 2014 for treatment of colorectal cancer. Int J Clin Oncol 20: 207-239, 2015.

24 Phillips RK, Hittinger R, Blesovsky L, Fry JS and Fielding LP: Local recurrence following 'curative'surgery for large bowel cancer: I. The overall picture. Br J Surg 71: 12-16, 1984.

25 Branagan G and Finnis D: Prognosis after anastomotic leakage in colorectal surgery. Dis Colon Rectum 48: 1021-1026, 2005.

26 Bell SW, Walker KG, Rickard MJFX, Sinclair G, Dent OF, Chapuis PH and Bokey EL: Anastomotic leakage after curative anterior resection results in a higher prevalence of local recurrence. Br J Surg 90: 1261-1266, 2003.
27 Petersen S, Freitag M, Hellmich G and Ludwig K: Anastomotic leakage: impact on local recurrence and survival in surgery of colorectal cancer. Int J Colorectal Dis 13: 160-163, 1998.

28 Eberhardt JM, Kiran RP and Lavery IC: The impact of anastomotic leak and intra-abdominal abscess on cancer-related outcomes after resection for colorectal cancer: a case control study. Dis Colon Rectum 52: 380-386, 2009.

29 Eriksen MT, Wibe A, Norstein J, Haffner J, Wing JN and Norwegian Rectal Cancer Group: Anastomotic leakage following routine mesorectal excision for rectal cancer in a national cohort of patients. Colorectal Dis 7: 51-57, 2005.

30 Nespoli A, Gianotti L, Bovo G, Brivio F, Nespoli L and Totis M: Impact of postoperative infections on survival in colon cancer patients. Surg Infect 7: 41-43, 2006.

31 Elaraj DM, Weinreich DM, Varghese S, Puhlmann M, Hewitt S and Carrol NM: The role of interleukin 1 in growth and metastasis of human cancer xenografts. Clin Cancer Res 12: 1088-1096, 2006.

32 Miki C, Konishi N, Ojima E, Hatada T, Inoue Y and Kusunoki $\mathrm{M}$ : C-reactive protein as a prognostic variable that reflects uncontrolled up-regulation of the IL-1-IL-6 network system in colorectal carcinoma. Dig Dis Sci 49: 970-976, 2004.

33 Strilic, B, Yang L, Albarran-Juarez J, Wachsmuth L, Han K, Muller UC, Pasparakis M and Offermanns S: Tumour-cellinduced endothelial cell necroptosis via death receptor 6 promotes metastasis. Nature 536: 215-218, 2016.

34 Murthy B, Thomson CS, Dodwell D, Shenoy H, Mikeljevic SJ, Forman D and Horgan K: Postoperative wound complications and systemic recurrence in breast cancer. Br J Cancer 97: 12111217, 2007.

35 Pierce BL, Ballard-Barbash R, Bernstein L, Baumgartner RN, Neuhouser ML and Wener MH: Elevated biomarkers of inflammation are associated with reduced survival among breast cancer patients. J Clin Oncol 27: 3437-3444, 2009.

36 Saito T, Kurokawa Y, Miyazaki Y, Makino T, Takahashi T, Yamasaki M, Nakajima K, Takiguchi S, Mori M and Doki Y: Which is a more reliable indicator of survival after gastric cancer surgery: Postoperative complication occurrence or C-reactive protein elevation? J Surg Oncol 112: 894-899, 2015.

37 Kelbel I and Weiss M: Anaesthetics and immune function. Curr Opin Anaesthesiol 14: 685-691, 2001.

38 Bruzzone A, Pinero CP, Castillo LF, Sarappa MG, Rojas P and Luthy IA: $\alpha 2$-Adrenoceptor action on cell proliferation and mammary tumour growth in mice. Br J Phamacol 155: 494-504, 2008.

39 Blumetti J, Chaudhry V, Cintron JR, Park JJ, Marecik S, Harrison JL, Prasad LM and Abcarian H: Management of anastomotic leak: Lessons learned from a large colon and rectal surgery training program. World J Surg 38: 985-991, 2014.

Received October 24, 2017

Revised November 9, 2017

Accepted November 13, 2017 